\title{
Endoscopic management of enteral tubes in adult patients - Part 2: Peri- and post-procedural management. European Society of Gastrointestinal Endoscopy (ESGE) Guideline
}

Authors

Paraskevas Gkolfakis ${ }^{1}$, Marianna Arvanitakis ${ }^{1}$, Edward J. Despott ${ }^{2}$, Asuncion Ballarin ${ }^{1}$, Torsten Beyna ${ }^{3 \odot}$, Kurt Boeykens $^{4}$, Peter Elbe ${ }^{5,6}$, Ingrid Gisbertz ${ }^{7}$, Alice Hoyois ${ }^{1}$, Ofelia Mosteanu ${ }^{8}$, David S. Sanders ${ }^{9}$, Peter T. Schmidt ${ }^{10,11}$, Stéphane M. Schneider ${ }^{12}$, Jeanin E. van Hooft ${ }^{13}$

Institutions

1 Department of Gastroenterology, Hepatopancreatology, and Digestive Oncology, CUB Hôpital Erasme, Université Libre de Bruxelles, Brussels, Belgium

2 Royal Free Unit for Endoscopy and Centre for Gastroenterology, UCL Institute for Liver and Digestive Health, The Royal Free Hospital, London, United Kingdom

3 Department of Gastroenterology and Therapeutic Endoscopy, Evangelisches Krankenhaus Düsseldorf, Germany

4 Nutrition Support Team, AZ Nikolaas Hospital, Moerlandstraat 1, 9100, Sint-Niklaas, Belgium

5 Department of Upper Digestive Diseases, Karolinska University Hospital, Stockholm, Sweden

6 Division of Surgery, Department of Clinical Science, Intervention and Technology (CLINTEC), Karolinska Institutet, Stockholm, Sweden

7 Department of Gastroenterology, Bernhoven Hospital, Uden, the Netherlands

8 Department of Gastroenterology, Iuliu Hatieganu University of Medicine and Pharmacy, Cluj-Napoca, Romania

9 Academic Unit of Gastroenterology, Royal Hallamshire Hospital \& University of Sheffield, United Kingdom

10 Department of Medicine (Solna), Karolinska Institutet, Stockholm, Sweden

11 Department of Medicine, Ersta Hospital, Stockholm, Sweden

12 Université Côte d'Azur, Centre Hospitalier Universitaire de Nice, Gastroentérologie et Nutrition, Nice, France

13 Department of Gastroenterology and Hepatology, Leiden University Medical Center, Leiden, The Netherlands

published online 21.12 .2020
Bibliography

Endoscopy 2021; 53: 178-195

DOI 10.1055/a-1331-8080

ISSN 0013-726X

(C) 2020. European Society of Gastrointestinal Endoscopy

All rights reserved.

This article ist published by Thieme.

Georg Thieme Verlag KG, Rüdigerstraße 14,

70469 Stuttgart, Germany

$\circledast$ Tables $1 \mathrm{~s}-3 \mathrm{~s}$

Supplementary material is available under

https://doi.org/10.1055/a-1331-8080

Corresponding author

Paraskevas Gkolfakis, MD, Department of Gastroenterology, Hepatopancreatology and Digestive Oncology, Erasme University Hospital, Université Libre de Bruxelles, Route de Lennik 808, 1070 Brussels, Belgium

Paraskevas.Gkolfakis@erasme.ulb.ac.be

\section{MAIN RECOMMENDATIONS}

ESGE recommends the "pull" technique as the standard method for percutaneous endoscopic gastrostomy (PEG) placement.

Strong recommendation, low quality evidence.

ESGE recommends the direct percutaneous introducer ("push") technique for PEG placement in cases where the "pull" method is contraindicated, for example in severe esophageal stenosis or in patients with head and neck cancer (HNC) or esophageal cancer.

Strong recommendation, low quality evidence.

ESGE recommends the intravenous administration of a prophylactic single dose of a beta-lactam antibiotic (or appropriate alternative antibiotic, in the case of allergy) to decrease the risk of post-procedural wound infection. Strong recommendation, moderate quality evidence. 
ESGE recommends that inadvertent insertion of a nasogastric tube (NGT) into the respiratory tract should be considered a serious but avoidable adverse event (AE).

Strong recommendation, low quality evidence.

ESGE recommends that each institution should have a dedicated protocol to confirm correct positioning of NGTs placed "blindly" at the patient's bedside; this should include: radiography, $\mathrm{pH}$ testing of the aspirate, and end-tidal carbon dioxide monitoring, but not auscultation alone. Strong recommendation, low quality evidence.

ESGE recommends confirmation of correct NGT placement by radiography in high-risk patients (intensive care unit
[ICU] patients or those with altered consciousness or absent gag/cough reflex).

Strong recommendation, low quality evidence.

ESGE recommends that EN may be started within 3-4 hours after uncomplicated placement of a PEG or PEG-J.

Strong recommendation, high quality evidence.

ESGE recommends that daily tube mobilization (pushing inward) along with a loose position of the external PEG bumper ( $1-2 \mathrm{~cm}$ from the abdominal wall) could mitigate the risk of development of buried bumper syndrome.

Strong recommendation, low quality evidence.

\section{SOURCE AND SCOPE}

This is Part 2 of a two-part Guideline from the European Society of Gastrointestinal Endoscopy (ESGE) on the endoscopic management of enteral tubes. This part addresses peri- and post-procedural considerations, including adverse events, as well as modalities of treatment and prevention.

\section{Introduction}

Enteral tube feeding is one of the cornerstones of nutritional support since it allows the provision of enteral nutrition (EN) in patients who have a functionally normal digestive tract but cannot meet their nutritional requirements because of inadequate oral intake [1]. Enteral tube insertion is a major part of the daily activity of an endoscopic unit; in the UK alone, for example, up to 17000 percutaneous endoscopic gastrostomies (PEGs) are placed annually [2]. Nevertheless, procedure-related morbidity and even mortality, remain an important concern, especially taking into consideration that the patient population involved is already frail [3]. Furthermore, there are still numerous controversies related to enteral tube insertion.

This evidence-based Guideline was commissioned by the European Society of Gastrointestinal Endoscopy (ESGE) and aims to address all major issues concerning endoscopic management of enteral tubes. This is the second of the two parts of the Guideline, and is dedicated to peri- and post-procedural considerations including adverse events (AEs) and their management. The first part, published as a separate manuscript [4] focused on definitions, enteral access and tube modalities, and preprocedural considerations, including preprocedural assessment and indications and contraindications for enteral tube insertion.

\section{Methods}

ESGE commissioned this Guideline (ESGE Guidelines Committee chair, J.v.H.) and appointed a guideline leader (M.A.), who in turn, invited the listed experts to participate in the project development. The topics and key questions were prepared by the coordinating team (M.A., P.G.) and then approved by the other members. The key topics consisted of preprocedural management (including indication/s), preprocedural assessment, periprocedural technical modalities, and post-procedural management (including AEs). The guideline development process included meetings and online discussions that took place from September 2019 to July 2020. 
The authors performed a systematic literature search through PubMed/MEDLINE, the Cochrane Library, and Embase for papers published on this topic up to January 2020. The search focused on fully published randomized controlled trials (RCTs) and meta-analyses. Retrospective analyses and case series were also considered for inclusion if they addressed topics not covered in prospective studies. For important outcomes, papers were individually assessed using the Grading of Recommendations Assessment, Development, and Evaluation (GRADE) system for grading of evidence levels and recommendation strengths, as described in the ESGE guideline development policy [5]. Each author developed draft proposals which were each discussed and debated electronically, and eventually through a face-to-face meeting held in January 2020 in Brussels, Belgium. After agreement among the authors on a final version, the manuscript was reviewed by two experts selected by the ESGE Governing Board and then disseminated to all ESGE-affiliated societies and individual members. After agreement on a final version, the manuscript was submitted for publication to the journal Endoscopy. All authors agreed on the final revised manuscript.

This Guideline is issued in 2020 and will be considered for review and update in 2024 or earlier, if new and relevant evidence becomes available. Any updates to the Guideline in the interim will be noted on the ESGE website: http://www.esge.com/esgeguidelines.html.

\section{Periprocedural management: endoscopic techniques for tube insertion}

\subsection{Nasojejunal tube (NJT) insertion}

\section{RECOMMENDATION}

ESGE suggests placing an NJT for short-term jejunal access, either through the nostril with an ultrathin transnasal gastroscope and a guidewire, or through the mouth by inserting the NJT directly into the biopsy channel of a gastroscope followed by an oronasal transfer.

Weak recommendation, very low quality evidence.

NJTs can be placed endoscopically using either of two techniques, depending on the type of tube used. One technique requires endoscopic guidance only. Dedicated narrow-bore (8- or $10-\mathrm{Fr}$ ) NJTs can be inserted directly through the working channel of a gastroscope or pediatric colonoscope, and positioned beyond the ligament of Treitz [6]. The endoscope is then pulled back while advancing the NJT under direct endoscopic visualization during withdrawal of the endoscope so that tube coiling is avoided. An oronasal transfer is then required to pass the NJT through the nose.

Another technique ("over the wire") involves passage of an ultrathin transnasal gastroscope through either nostril. A guidewire is then inserted down the biopsy channel of the ultrathin gastroscope and under direct endoscopic and fluoroscopic guidance; this is then passed beyond the ligament of
Treitz [6]. Once the guidewire is in the desired position, the endoscope is withdrawn, while simultaneously advancing the guidewire in a "one-to-one fashion," to maintain its distal position without looping or coiling. The stomach should be kept decompressed as the scope is initially passed and also during withdrawal, in order to minimize gastric volume. Finally, the NJT is threaded over the guidewire and advanced using a Seldinger technique, while putting slight tension on the guidewire, until it reaches the jejunum. Clipping of the tip of the NJT to the mucosa has been shown to reduce displacement [7].

\subsection{PEG insertion}

\section{RECOMMENDATION}

ESGE recommends the "pull" technique as the standard method for PEG placement.

Strong recommendation, low quality evidence.

\section{RECOMMENDATION}

ESGE recommends the direct percutaneous introducer ("push") technique for PEG placement in cases where the "pull" method is contraindicated, for example in severe esophageal stenosis or in patients with head and neck cancer (HNC) or esophageal cancer.

Strong recommendation, low quality evidence.

\section{RECOMMENDATION}

ESGE recommends percutaneous gastropexy of the anterior gastric wall to the anterior abdominal wall with $\mathrm{T}$ fasteners or a dedicated suturing device prior to "push" PEG placement, in order to prevent deflection of the stomach and tube misplacement.

Strong recommendation, low quality evidence.

\subsubsection{Overview}

In principle, there are two major techniques for PEG tube placement: the peroral "pull" technique and the direct percutaneous "push" procedure. The success rate of PEG tube placement is as high as $99.5 \%$ (range $76 \%-100 \%$ ). Reasons for failure include inadequate transillumination, complete oropharyngeal or esophageal obstruction, and previous gastric resections [8].

The "pull-string" or "pull" method introduced by Gauderer et al. in 1980 has established itself as the most widely accepted technique for PEG placement in clinical practice [9]. PEG placement using the "pull" method has replaced surgical gastrostomy $[10,11]$ since it is safer and more cost-effective, with lower procedure-related mortality $(0.5 \%-2 \%)$ and complication rates $[12,13]$.

The direct percutaneous technique, namely the "introducer" or "push" PEG, using a balloon-type tube placed transabdominally into the stomach, was first described by Russell et al. [14] 
for patients in whom the standard "pull" technique either cannot be used (e.g. because of presence of an esophageal stricture) or would involve an increased risk during passage of the internal bumper (e.g. risk of implantation metastasis in malignant diseases, mainly in primary squamous cell pharyngoesophageal cancer) [15]. The main problem initially associated with this technique was deflection of the stomach wall during puncture, combined with the risk of tube misplacement. However, its safety has since been improved through the use of an intragastrically positioned T-fastener to fix the stomach to the abdominal wall, under fluoroscopic or endoscopic guidance $[16,17]$. A new, safe-introducer method has also become available recently. This allows the combination of a double gastropexy with a peel-away trocar-sheath introducer, to effectively secure the stomach wall to the anterior abdominal wall $[18,19]$.

Different types of enteral tubes are placed according to the type of insertion technique: enteral tubes with an internal bumper are used for the "pull" technique, whereas balloon-type tubes are used for the "push" technique.

\subsubsection{General preparation [20]}

- Patient fasting overnight (6 hours for solids and 2 hours for clear liquids, longer if there is impaired gastric motility)

- Antibiotic prophylaxis (single intravenous dose of a betalactam antibiotic, or suitable alternative in case of allergy, according to local policy; see Recommendation, section 3.4)

- PEG insertion is performed using a strict sterile/aseptic technique (skin disinfection, sterile surgical drapes, sterile gloves, sterile dressing, etc.)

\subsubsection{Description of the "pull" technique $[10,21]$}

Two operators are required to insert a PEG tube: the endoscopist and the second operator who performs abdominal wall puncture and thread/wire traction. An upper gastrointestinal (GI) endoscopy is performed with the patient in the supine position. During endoscopy, the stomach is fully insufflated (ideally with carbon dioxide $\left[\mathrm{CO}_{2}\right]$ ) in order to appose the stomach to the abdominal wall and displace any interposed viscera.

The desired puncture site (on the anterior gastric wall in the region of the distal corpus) is then identified by means of transillumination and finger indentation (by the second operator). The second operator then marks the skin over the chosen site, and after adequate skin cleansing and infiltration with local anesthetic, a green (21-G) seeker needle, attached to a $10-\mathrm{mL}$ syringe (half-filled with $0.9 \%$ saline) is inserted vertically through the skin and abdominal wall into the insufflated stomach. It is important for the second operator to maintain negative pressure on the syringe plunger as the needle is advanced, and to observe for any gas bubbles, which may be aspirated into the syringe (needle aspiration technique). Gas bubbles within the syringe that are seen earlier than when the needle is seen to puncture the gastric wall (on the endoscopic view) may indicate that an interposed viscus may have been punctured inadvertently and this should raise concern to seek an alternative site of puncture.

Once the seeker needle is safely in place, the second operator makes an appropriate incision over this puncture site, and the introducer trocar (and its overlying cannula/sheath) is then inserted under direct endoscopic visualization with constant endoscopic gaseous insufflation of the stomach. The dedicated thread/wire (found within the PEG kit) is then passed through the cannula/sheath and into the stomach by the second operator, where it is grasped by the endoscopist using a small endoscopic snare or grasping forceps. Once grasped securely, the thread/wire is then drawn out through the mouth together with the gastroscope by the endoscopist. The thread/wire loop is then secured tightly with a simple loop to the corresponding thread/wire loop provided at the external end of the PEG tube.

The second operator then applies continuous traction to the thread/wire through the abdominal wall puncture site, and the thread/wire-attached PEG tube is drawn down the esophagus and stomach and out through the puncture site until the internal fixation bumper apposes the anterior wall of the stomach. Provided that positioning of the PEG tube has been conducted without complications, the position of the internal bumper may be confirmed endoscopically, although this step is optional and not strictly necessary [22].

\subsubsection{Description of the "introducer" or "push" technique (PEG with gastropexy) $[18,19]$}

Again, two operators are required for the "push" or "introducer" technique: the endoscopist and second operator. The procedure is done under strict aseptic/surgical conditions and local anesthesia. Percutaneous puncture of the stomach is performed through a previously determined area of the anterior gastric wall, by means of a dedicated double-lumen or T-fastener gastropexy device under direct endoscopic visualization.

The same steps as the "pull" technique described above are used to identify a safe and adequate puncture site with a seeker needle and attached syringe. With ongoing gaseous insufflation of the stomach by the endoscopist, after adequate skin cleansing and local anesthetic infiltration, the second operator places two or three gastropexies (in a triangular fashion) at a distance of $20 \mathrm{~mm}$ from one another. With maintenance of full gastric insufflation by the endoscopist, the second operator, securely fastens the gastropexies and makes a skin incision within the area between the gastropexies. The second operator then uses the dedicated trocar and overlying peel-away sheath for puncture of the abdominal wall and anterior gastric wall through the skin incision. This is done gently and under direct endoscopic visualization and with careful orientation of the trocar into the gastric lumen, in order to avoid inadvertent laceration/puncture of the posterior gastric wall. The metal trocar, is then removed, leaving the dedicated peel-away sheath in situ within the puncture tract.

A balloon-type PEG tube is then introduced through the sheath and once the tube balloon has been filled with sterile water under endoscopic visualization, the sheath is peeled away, leaving the tube and fastening external bumper in situ. 


\subsection{Percutaneous endoscopic gastrostomy with jejunal extension (PEG-J) and direct percutaneous endoscopic jejunostomy (D-PEJ) insertion}

\section{RECOMMENDATION}

ESGE recommends placement of a jejunal feeding tube either through a PEG-J or D-PEJ in patients needing longterm EN and through a jejunal route. The choice between PEG-J and D-PEJ would depend on patient characteristics (anatomy, need for gastric aspiration, pre-existing PEG), as well as local expertise.

Strong recommendation, low quality evidence.

Long-term jejunal feeding can be achieved endoscopically through jejunal tube extensions passed through a PEG (PEG-J) or through direct percutaneous endoscopic jejunostomy (DPEJ) $[23,24]$.

PEG-J placement beyond the ligament of Treitz can be carried out by pushing a jejunal extension feeding tube through a previously placed PEG using a "beneath the scope" [27] or "over the wire" tube technique, under fluoroscopic guidance [24, $28-31$ ]. Extension jejunal tubes are limited to $9 \mathrm{Fr}-12 \mathrm{Fr}$ in diameter, depending on the size of the previously placed PEG tube; they are approximately $60 \mathrm{~cm}$ in length. The extension tube may be grasped endoscopically with a forceps or a snare and dragged into the jejunum ("beneath the scope") or advanced over an endoscopically placed guidewire or stiffening catheter ("over the wire").

PEG-J tubes have an initial high success rate of up to $93 \%$ [ 8 , $20,23,24]$. However, functional success is limited because of frequent retrograde migration of the jejunal extension tube into the stomach [32] and tube dysfunction caused by kinking or obstruction (as the jejunal tube maximum diameter is restricted to $12 \mathrm{Fr}$ ) $[23,24]$. Endoscopically placed clips may secure the distal end of the tube to reduce the risk of retrograde migration [33]. Additionally, the initial PEG site should be near the antrum, to create a better angle of insertion and reduce the distance between the abdominal wall and the pylorus [6]. Finally, a nonrandomized, comparative study in patients with native gastric anatomy (56 patients with D-PEJ and 49 with a PEG-J) concluded that feeding tube patency lasted longer and fewer endoscopic re-interventions were required for patients with D-PEJ as compared with PEG-J [34].

D-PE] placement is a modification of the "pull" PEG technique and is usually indicated for long-term jejunal EN [24, $35-38$ ]. For endoscopic visualization a push enteroscopy is performed with a standard or, preferably, a pediatric colonoscope, or with a dedicated push enteroscope. Some reports have shown a higher success rate using single-balloon [39] or double-balloon enteroscopy [40].

Once jejunal transillumination and finger indentation are observed on the anterior abdominal wall (indicating the identification of a favorable superficial jejunal loop), this is used as an indicator of the scope's position within the jejunum. In an iden- tical fashion to that described for the "pull" PEG insertion technique, described above, after adequate cleansing of the skin and using a strict aseptic technique, a green (21-G) seeker needle is used for infiltration of local anesthetic by the second operator. The seeker needle is then used to determine an optimal position prior to the trocar/needle pass. Grasping the tip of the seeker needle with a snare or a forceps helps to stabilize the jejunal segment and allows proper orientation for insertion of the larger trocar/needle alongside the indwelling seeker needle [41]. As described for the "pull" PEG insertion technique, a dedicated thread/wire is advanced through the plastic sheath by the second operator (after the trocar has been withdrawn). This thread/wire is then grasped by the awaiting endoscopist using a forceps or small snare, and the procedure is completed as described for the "pull"-type PEG placement. Though similar to PEG placement, D-PEJ is a considerably more challenging technique. In the two largest retrospective cohorts on D-PEJ outcome involving a total of 738 patients, successful placement was achieved in $68 \%-83 \%[35,38]$; this may be higher if a double-balloon or single-balloon enteroscope is used [39].

The choice between a PEG-J and D-PEJ depends on local expertise, patient anatomy, pre-existing abdominal surgery, the presence of a pre-existing PEG, the need for concomitant gastric aspiration (favors the PEG-J), and the risk of retrograde migration of the jejunal extension (favors D-PEJ) [6].

\subsection{Use of prophylactic antibiotic administration before insertion of a percutaneous tube (PEG) PEG-J/D-PEJ)}

\section{RECOMMENDATION}

ESGE recommends the intravenous administration of a prophylactic single dose of a beta-lactam antibiotic (or appropriate alternative antibiotic, in the case of allergy) to decrease the risk of post-procedural wound infection. Strong recommendation, moderate quality evidence.

A number of RCTs have highlighted the valuable role of preprocedural antibiotic administration for reduction of peristomal infections [19,42-54]. In the largest of these studies, which compared single-dose intravenous cefuroxime (750 mg) $(n=50)$ with placebo $(n=51)$ given 30 minutes before PEG placement, peristomal wound infection was significantly reduced during the first week in patients who had received the antibiotic as compared with the placebo group [48]. Pooled data from one meta-analysis including 10 RCTs (1059 patients), showed that prophylactic penicillin- or cephalosporin-based treatment decreases the risk of post-procedural wound infection [55]. The highest relative risk reduction was achieved with administration of penicillin rather than cephalosporin (13\% vs. $10 \%$, respectively) [55].

In the most recent Cochrane database systematic review of 12 studies ( $n=1271$ patients) comparing intravenous antibiotic administration prior to PEG insertion with placebo, no intervention, or simple skin antiseptic, a significant benefit for antibiotic 
administration was detected (odds ratio [OR] 0.36, $95 \% \mathrm{Cl} 0.26$ 0.50 ) [56]. The optimal timing of antibiotic administration has not been determined, but based on the methodology of these studies, intravenous administration 30 minutes before the procedure appears to be reasonable [57] (Tables 1(a)s, 1(b)s, available online-only in Supplementary material). Nevertheless, in another RCT, a single 20-mL dose of an oral solution of co-trimoxazole deposited via the PEG catheter immediately after insertion has been shown to be at least as effective as preprocedural intravenous cefuroxime prophylaxis $[43,58]$. This regimen can be proposed in patients with penicillin-related allergy. Finally, in patients who are already receiving antibiotics, no specific antibiotic prophylaxis is required [20].

Further to prophylactic antibiotic administration, the adherence to a full sterile, aseptic technique and avoidance of excessive pressure between the skin and the external bumper have also been shown to decrease the risk of wound infection [59].

\subsection{Periprocedural adverse events (AEs)}

\section{RECOMMENDATION}

ESGE recommends that periprocedural AEs related to endoscopic placement of any enteral tube should be considered to also carry the intrinsic risks relating to the sedation/general anesthesia used.

Strong recommendation, low quality evidence.

\section{RECOMMENDATION}

ESGE recommends that inadvertent insertion of an NGT into the respiratory tract should be considered a serious but avoidable AE.

Strong recommendation, low quality evidence.

\section{RECOMMENDATION}

ESGE recommends that visceral perforation, peritonitis, and bleeding should be considered as potential periprocedural AEs of PEG, PEG-J, or D-PEJ tube placement. Strong recommendation, low quality evidence.

Periprocedural AEs are rare and rates should be of the order of $<0.5 \%[20,60]$, if strict contraindications are adhered to [20, $61,62]$.

Sedation/general anesthesia. As with all other endoscopic procedures performed under sedation or general anesthesia, endoscopic placement of enteral tubes carries cardiovascular and pulmonary risks, which directly relate to the sedation/anesthetic itself [63]. These include risks of hemodynamic instability, dysrhythmias and aspiration pneumonitis. The rate of aspiration AEs occurring periprocedurally has been reported to be around $1 \%$, and risk factors for this include the supine posi- tion, type and dose of sedation used, neurologic impairment, and advanced age $[20,60]$.

NGT insertion is mostly performed "blindly" at the patient's bedside. AEs related to NGT insertion include epistaxis, coiling of the tube within the esophagus, and most importantly, inadvertent placement into the respiratory tract $[64,65]$; this occurs infrequently but may potentially have fatal consequences. A retrospective study reported a $1.3 \%$ incidence $(n=50)$ of misplacement in over 2000 NGT insertions in adults over a period of 4 years; mechanical ventilation and altered mental status appear to be risk factors [66].

NJTs are placed in the endoscopy suite, with or without fluoroscopy. The main periprocedural complications concerning NJTs relate to incorrect placement, tube kinking, and periprocedural dislodgment [7]. NJTs with a spiral end to facilitate bedside placement in patients with intact gastric motility are also available [67].

PEG, PEG-J, and D-PEJ tubes. Periprocedural AEs that are not related to sedation are rare $(0.1 \%)$, albeit potentially serious, and include: perforation of interposed viscera (including the colon, small bowel, liver, and spleen), peritonitis, and bleeding [20,60,62].

Although perforation of an interposed viscus is rare, transient subclinical pneumoperitoneum is a common finding following PEG insertion, occurring in up to $56 \%$ of procedures and generally not of any clinical significance [68]. Conversely, fullblown peritonitis presents as abdominal pain, leucocytosis, ileus, and fever. It can result in significant morbidity if not identified and treated early [20].

Risk factors for bleeding include anticoagulation and previous anatomic alteration [20]. Immediate gastric bleeding after PEG placement is very rare $(0.3 \%)$ and is usually caused by injury of the left gastric or gastroepiploic arteries or one of their branches [69]. Severe intraperitoneal bleeding can also occur because of liver laceration and this presents as severe postprocedural hypotension with or without peritonitis [70]. PEG-] placement poses the additional risk of retrograde migration of the jejunal extension back into the stomach, and this may lengthen the duration of the procedure [60]. Finally, D-PEJs have a slightly higher rate of periprocedural AEs, reaching $2 \%$; these include bleeding and small-bowel perforation [35, 38].

\subsection{Prevention and management of periprocedural AEs related to enteral tube placement}

\section{RECOMMENDATION}

ESGE recommends careful preprocedural selection, preassessment, and optimization of any underlying patient comorbidities in order to reduce any sedation/general anesthetic risks. Should any sedation/general anesthetic periprocedural AEs arise, these should be managed using specific measures that address the event, with a low threshold to abandon or postpone the procedure.

Strong recommendation, low quality evidence. 


\section{RECOMMENDATION}

ESGE recommends careful attention to safe procedure technique during PEG, PEG-J, or D-PEJ placement, in order to reduce the risk of inadvertent injury to any interposed viscera. In the case of any ongoing concern relating to incorrect placement/perforation, the patient's condition should be stabilized and there should be a low threshold to proceed to urgent, computed tomography (CT) scanning.

Strong recommendation, low quality evidence.

\section{RECOMMENDATION}

ESGE recommends close monitoring after PEG, PEG-J or D-PEJ tube placement, with due attention to unexplained tachycardia and hypotension. Should these occur, the patient should be resuscitated and transferred for urgent $C T$ mesenteric angiography to rule out any intra-abdominal bleeding.

Strong recommendation, low quality evidence.

\section{RECOMMENDATION}

ESGE recommends that each institution have a dedicated protocol to confirm correct positioning of NGTs placed "blindly" at the patient's bedside, including radiography, $\mathrm{pH}$ testing of the aspirate, and end-tidal carbon dioxide monitoring, but not auscultation alone.

Strong recommendation, low quality evidence.

\section{RECOMMENDATION}

ESGE recommends confirmation of correct NGT placement by radiography in high-risk patients (intensive care unit [ICU] patients or those with altered consciousness or absent gag reflex).

Strong recommendation, low quality evidence.

Sedation- or general anesthesia-related AEs. In order to reduce any sedation- or general anesthesia-related risk, careful patient selection should be undertaken. This should include preassessment of the patient and optimization of their overall condition and underlying comorbidities, which may pose additional risks $[63,71]$. The use of multidisciplinary nutrition support teams has been shown to be helpful with patient selection and choice of type of enteral access, and to help reduce overall AEs [72]. Moreover, the endoscopist can further minimize the risk by avoiding excessive sedation, aspirating the gastric contents before the procedure, suctioning previously insufflated gas after the procedure, and by performing the procedure in a time-efficient manner [20].
Should any sedation/general anesthesia-related AE occur, the procedure should be paused or abandoned, and specific measures to address the event should be undertaken. Cardiopulmonary resuscitation equipment and essential drugs (including reversal agents) should be readily available for immediate use [63].

NGT placement: periprocedural AEs In order to minimize the risk of inadvertent placement into the respiratory tract, a widely applied technique is to auscultate for sounds of airflow at the end of the tube or to place the tip into a glass of water to observe for bubbles. However, there is not always enough air movement to make this a safe strategy to adopt and other methods to confirm placement are therefore mandatory. Similarly, auscultation methods are not accurate enough to assess whether the tube is within the lung or the GI tract, with accuracy rates as low as $34.4 \%$ [73]. The gold standard for confirming correct placement is chest radiography with visualization of the entire length of the tube according to previous guidelines, ranging from "always required" to "use when other methods fail” $[64,74-76]$.

Additional methods can be used to lower the number of radiographs needed to confirm correct positioning; these include $\mathrm{pH}$ sensors or end-tidal carbon dioxide $\left(\mathrm{ETCO}_{2}\right)$ monitoring [64]. An aspirate $\mathrm{pH}$ of $\leq 5.5$ as well as the appearance of the fluid is also commonly used to confirm that the NGT is correctly positioned within the stomach $[64,75]$. Nevertheless, in a prospective study including 97 and 106 samples taken during gastroscopy and bronchoscopy, respectively, the sensitivity for correctly identifying gastric samples at $\leq 5.5$ was $68 \%$ and the specificity was $79 \%$ [77]. Although proton pump inhibitors do not seem to be associated with $\mathrm{pH}>5$, there was a considerable overlap between esophageal and gastric aspirates, therefore limiting the differentiation between correct gastric positioning and tube misplacement with retrograde coiling into the esophagus [78].

$\mathrm{ETCO}_{2}$ monitoring using capnography or colorimetric capnometry has also been used to assess tube location [64]. A metaanalysis on 456 nasogastric tube insertions, mainly in an ICU setting with mechanically ventilated patients, revealed a sensitivity ranging from 0.88 to 1.00 , and a specificity from 0.95 to 1.00 [79].

Finally, nose-earlobe-xiphoid distance is frequently used to estimate the insertion length of nasogastric tubes. Nevertheless, this method has been proven inaccurate, with underestimation of insertion length in more than $20 \%$ of patients and overestimation of insertion length in $17.2 \%$ of patients [80]. Underestimating the insertion length may lead to malpositioning of the tube in the distal esophagus and therefore increase the risk of reflux and pulmonary aspiration.

Marking the tube at the exit site from the nares can serve as an indicator of whether or not the tube has been partially removed, but this cannot exclude a retrograde migration of the tip into the esophagus [64].

NJT placement: periprocedural AEs. During endoscopic placement, every effort should be made to pass the tube beyond the ligament of Treitz, in order to reduce any risk of retrograde dislodgment back into the stomach. Functional patency 
of the tube should also be checked after endoscopic placement by regular assessment of ease of tube-flushing; this allows immediate correct repositioning and avoidance of any persistent obstructive kinking of the tube.

PEG, PEG-J, and D-PEJ: periprocedural AEs. In order to reduce periprocedural risk in PEG, PEG-J, and D-PEJ placement, in addition to careful patient selection and review of any preprocedural cross-sectional imaging [81], certain technical periprocedural considerations described below, may also help $[20,60]$.

Perforation of an interposed viscus. Preventive maneuvers include: sufficient insufflation of the stomach to enhance its apposition to the abdominal wall; the achievement of good transillumination; external finger indentation (as viewed endoscopically); and the use of a green (21-G) seeker needle attached to a syringe half-filled with saline (the "safe track" technique) $[20,60,62]$. Prior to any attempt at insertion of the trocar, the seeker needle should be used, with negative pressure applied to the syringe plunger as the seeker needle is advanced through the skin. Any gas bubbles seen to appear within the syringe before endoscopic visualization of the seeker needle, may indicate interposition of another viscus (e.g. the colon or a small-bowel loop) and the targeted area of choice should be changed, or the procedure abandoned. In the case of any ongoing concern relating to incorrect placement/perforation, the patient's condition should be stabilized and there should be a low threshold to proceeding to urgent CT scanning and involvement of the surgical team [20].

Bleeding. Despite all precautions and appropriate technique, PEG, PEG-J, and D-PEJ placement all carry the risk of precipitating significant bleeding. This mainly relates to the use of the percutaneously inserted trocar/needle, which may inadvertently puncture large vessels within the abdominal wall, visceral surface/wall, or mesentery. Although cutaneous and intraluminal bleeding are immediately recognized and may be treated with external pressure or endotherapy, respectively, intraperitoneal major bleeding from other injured vessels may remain occult and strict vigilance regarding the patient's vital parameters is therefore required, for at least the first 2 hours postprocedure [3]. Particular attention should be paid to unexplained tachycardia and hypotension. Should these occur, the patient should be resuscitated and transferred for an urgent CT mesenteric angiogram to rule out any intra-abdominal hemorrhage.

\subsection{Appropriate documentation of endoscopic insertion of enteral tubes}

\section{RECOMMENDATION}

ESGE recommends appropriate documentation regarding endoscopically placed enteral tubes.

Strong recommendation, low quality evidence.
The procedure report should include the following elements, where applicable: indication for the procedure; type and dose of sedation/general anesthesia use; type of insertion technique; the number of attempts/trocar passes; type/gauge/ brand of tube used; and serial number/batch of tube used (with the corresponding traceability sticker placed in the patient notes). There should also be documentation of antibiotic cover; type and dose of local anesthetic infiltrated into the skin or abdominal wall; and clear documentation of the internal bumper-to-skin distance, for reference.

\section{Post-procedural management}

\subsection{Using the percutaneous enteral tube (PEG, PEG- J, D-PEJ) for the first time after endoscopic placement}

\section{RECOMMENDATION}

ESGE recommends that EN may be started within 3 to 4 hours after uncomplicated placement of an PEG or PEG-J. Strong recommendation, high quality evidence.

\section{RECOMMENDATION}

ESGE suggests that EN may be started within 24 hours after uncomplicated placement of a D-PEJ.

Weak recommendation, low quality evidence.

Two meta-analyses, including RCTs with 355 and 467 patients, respectively, showed no differences in terms of morbidity (local infections, diarrhea, bleeding, fever, gastroesophageal reflux, vomiting, stomatitis, leakage) or early mortality $(<72$ hours) when feeding was started within 3 to 4 hours from PEG placement as compared with delayed commencement of EN (>24 hours) [82,83] (Table 2s). One meta-analysis revealed a statistically significant increase in gastric residual volume in the case of early feeding (OR $1.80,95 \% \mathrm{Cl} 1.02-3.19 ; P=$ 0.04 ), but without any clinical consequences [82]. Moreover, a prospective comparative study suggested that early feeding after PEG tube insertion could also help reduce inpatient stay [84]. Finally, in the two largest series of D-PEJ, the initiation of enteral feeding was reported to be within 4 to 24 hours after placement $[35,38]$.

\subsection{Post-procedural AEs, mortality, and associated risk factors relating to percutaneous enteral tube (PEG/PEG-J/D-PEJ) insertion}

\section{RECOMMENDATION}

ESGE recommends cautious preprocedural patient selection since patient characteristics are related to early and long-term PEG-associated mortality.

Strong recommendation, low quality evidence. 


\section{RECOMMENDATION}

ESGE recommends considering patient age, the presence of stroke as an indication, and preprocedural nutritional and inflammatory status as risk factors for early and long-term PEG-related mortality.

Strong recommendation, low quality evidence.

Although PEG placement is considered a safe procedure if all recommended precautions are applied, post-procedural AEs may still occur. The $\mathrm{AE}$ incidence rate ranges from $4.8 \%$ to $26.2 \%$ [85-87], while early (30-day) and 1-year mortality are reported to be of the order of $1.8 \%-23.5 \%[58,85,87-90]$ and $35 \%-55 \%[85,86,90,91]$, respectively. AEs are usually minor with major ones being reported in up to $2 \%$ of cases [58].

In a retrospective study of more than 400 patients treated by either "pull" or "introducer or push" PEG, multivariate analysis revealed that underlying malignancy was a predictor of early ( $\leq 7$ days) complications, while age $\geq 70$ years and diabetes mellitus predicted late ( $>7$ days) post-procedural AEs [87]. In the same analysis thrombocytopenia $(<100000 / \mu \mathrm{L})$ and a high C-reactive protein (CRP) level $(\geq 5 \mathrm{mg} / \mathrm{dL}$ ) were associated with increased 30-day mortality rate, while patients suffering from other neurological diseases (apart from stroke) had lower 30-day mortality risk as compared with patients suffering from stroke or underlying malignancy [87]. Among the 20 patients who died within 30 days following PEG placement, pneumonia was the most frequently identified cause of death [87].

In a large retrospective study $(n=1625)$ low serum albumin $(<31.5 \mathrm{~g} / \mathrm{L})$ and increased CRP $(>21.5 \mathrm{mg} / \mathrm{L})$ levels were associated with an increased 30-day mortality, with patients carrying both factors having an even shorter median survival [92]; similar results were also identified in a prospective, large cohort study [88]. Higher CRP levels were found to be the only independent risk factor for 30-day mortality in another study from Portugal ( $n=157)$; the definitive cutoff value was a CRP level of $\geq 35.9 \mathrm{mg} / \mathrm{dL}$ [93].

As mentioned above, stroke patients appear to have worse survival and this was confirmed in another retrospective study of 500 patients [90]. In this cohort of patients with neurological disease, the median survival was shorter in patients who were suffering from stroke (11.4 vs. 27.1 months, $P=0.014$ ). Moreover, in the subgroup of stroke patients, multivariate analysis identified preprocedural neutrophil percentage and late AE as negative independent prognostic factors, while prophylactic antibiotic usage and hyperlipidemia were found to be inversely correlated to mortality [90]. Similarly, in another cohort $(n=$ 100 ), patients undergoing PEG placement because of underlying neurologic disease had a significantly higher 6-month mortality as compared with patients treated for underlying malignancy (60\% vs. $27.7 \%, P=0.002$ ) [86].

In a recent study from Israel $(n=272)$ multivariate analysis identified older age, higher creatinine levels and elevated CRPto-albumin ratio as significant predictors of short-term mortality after PEG placement [89]. Finally, in two further recent large studies, from Italy and Sweden ( $=950$ and $n=495$, respectively), age and lower body mass index (BMI) were identified as risk factors for mortality [58, 85] (Table 3s).

\subsection{Post-procedural AEs related to enteral tube insertion}

\section{RECOMMENDATION}

ESGE recommends considering wound infection, buried bumper syndrome, peristomal leakage, tube dislodgment, and fistula formation as the main post-procedural complications related to PEG/PEG-J/D-PEJ.

Strong recommendation, low quality evidence.

Several post-procedural PEG AEs have been described in detail elsewhere $[4,60,62]$. They include infection-related AEs, namely wound infection and necrotizing fasciitis; complications related to dysfunction of the enteral access tract, namely buried bumper syndrome (BBS); peristomal leakage; PEG site herniation; tube dislodgment; gastric outlet obstruction; and fistula formation.

\subsubsection{Wound infection}

\section{RECOMMENDATION}

ESGE recommends local antiseptic measures and daily dressing changes for minor (nonextending) wound infections and broad-spectrum antibiotics for more severe infections.

Strong recommendation, low quality evidence.

Infectious complications are considered to be the most common PEG-associated AEs $[94,95]$. In the era of prophylactic antibiotic use, the incidence of infection has decreased significantly $[58,85]$, albeit this remains high, especially in developing countries [96]. Infections are usually mild and limited to the peristomal PEG site, but less frequently, more serious infectious complications including abscess formation and necrotizing fasciitis may occur [3]. In the case of local wound infection, the clinical examination reveals a painful PEG site with erythema, induration and potential purulent exudate with or without signs of systemic inflammation. Mild peristomal erythema is commonly found and should not be considered as an infection.

For mild wound infection, treatment consists of local antiseptic measures and regular dressing changes. Broad-spectrum antibiotics should be administered, either orally if the diagnosis is made early after PEG placement (within 3-5 days) or intravenously in cases of later diagnosis or in those with a more severe presentation (e.g. systemic sepsis); antibiotic therapy should be guided by sample culture and sensitivity results. Surgical intervention is reserved for severe complications, including abscesses, peritonitis, or necrotizing fasciitis; the lastmentioned is a rare but potentially fatal AE after PEG insertion, 
that requires both antibiotic coverage and appropriate surgical debridement of the infected area $[97,98]$.

\subsubsection{Buried bumper syndrome (BBS)}

\section{RECOMMENDATION}

ESGE recommends that daily tube mobilization (pushing inward) along with a loose position of the external PEG bumper ( $1-2 \mathrm{~cm}$ from the abdominal wall) could mitigate the risk of buried bumper syndrome (BBS) development. Strong recommendation, low quality evidence.

BBS refers to the migration of the internal PEG bumper along the PEG tract, ending up within the gastric or abdominal wall with consequent overgrowth of gastric mucosa over the bumper [99]. It occurs in $1 \%-4 \%$ of cases $[85,100]$. BBS is caused by excessive traction between the internal PEG bumper and the abdominal wall that results in local pressure necrosis and subsequent migration [101]. This traction is the result of excessive, usually long-term, PEG tightening post-placement; other associated, potentially contributory factors include obesity, weight gain, and chronic cough [102].

BBS is diagnosed clinically by visualization and palpation of the subcutaneously located bumper, and by endoscopic or CT demonstration of the migrated internal bumper. Pain at the PEG site, loss of tube patency, and leakage around the PEG site are other common findings in patients with BBS. BBS may lead to other complications such as bleeding, peritonitis, and abscess formation $[100,103]$.

In cases of incomplete BBS, where part of the internal bumper is still visible and the tube remains patent, the buried bumper can be effectively pushed back into the stomach by using a dilator [104] or the push - pull T technique [105, 106]. In cases of complete BBS, endoscopically guided application of electrosurgical incisions using a sphincterotome, a needle-knife, or recently developed dedicated devices can be used [104,107109]. For complicated extragastric cases [110] or when endoscopy fails to release the trapped bumper, surgery remains an option. If indicated, a new PEG should be placed a couple of weeks later, at a different site, in order to allow adequate healing of the previous tract. However, cases of simultaneous insertion of a new balloon-type tube have also been described [111, 112].

Initial ( 3 - 5 days after insertion) tighter fixing of the abdominal wall bolster and the internal bumper, aimed to prevent leakage, should be followed by a looser position of the external skin bumper with a $1-2 \mathrm{~cm}$ distance from the abdominal wall, in order to mitigate the risk of BBS [103]. Appropriate daily care, tube mobilization (pushing inward), and placement of a gauze pad under the external bolster could also reduce the risk of BBS development [59]. Rotation of the tube should be avoided in cases of PEG-J and D-PEJ in order to avoid jejunal extension dislodgment and jejunal volvulus, respectively $[35,36]$.

\subsubsection{PEG site herniation}

PEG site herniation is a rare complication associated with PEG placement [113-118]. It presents with ongoing leakage, bulging, or pain at the PEG site, either while the tube remains in situ or when it is removed. Choosing the optimal site for PEG placement and, if possible, avoiding the weakest points of the abdominal wall (e.g. the linea alba/midline) may reduce the risk of herniation. Appropriate surgical management of the hernia may be required.

\subsubsection{Peristomal leakage}

\section{RECOMMENDATION}

ESGE suggests that an effort to treat any underlying predisposing disease should be made in the case of peristomal leakage. Local treatment with absorbing agents, stoma adhesive powder, and zinc oxide may reduce local skin irritation.

Weak recommendation, low quality of evidence.

\section{RECOMMENDATION}

ESGE suggests, that in the case of persistent leakage, the PEG tube should be removed and a new PEG should be placed at a different site.

Weak recommendation, low quality of evidence.

Peristomal leakage of gastric content may occur in up to $2 \%$ of cases following PEG placement [119]. Usually this appears early after PEG insertion but delayed leakage may also occur [94]. Different risk factors have been identified. Among them, local factors include skin infection, excessive cleaning with abrasive products, increased gastric acid secretion, gastroparesis, side torsion of the tube, BBS, increased tension between internal and external bumpers, and presence of granulomatous tissue within the tract. Systemic conditions such as diabetes mellitus, immunodeficiency, or severe malnutrition, which prevent adequate wound healing $[95,120]$, are also associated with peristomal leakage.

Optimal management of peristomal leakage includes treatment of any underlying predisposing disease and local treatment with absorbing agents. Antisecretory medication and prokinetics can also be used to reduce gastric acidity and stasis. The use of stoma adhesive powders or zinc oxide application has been proposed to reduce local skin irritation [20], while topical application of silver nitrate or argon plasma can be used in the case of a coexisting granuloma [62]. For persisting delayed peristomal leakage EN should be interrupted, and the tube should either be removed temporarily (24 to 48 hours) to permit partial closure, using a guidewire to secure tract patency, or there should be complete removal of the tube and replacement at another site of the abdominal wall, once the previous tract has healed completely $[59,120]$. In the case of delayed gastric emptying despite prokinetics, a PEG-J or D-PEJ may be 
considered. For balloon-type tubes with peristomal leakage, it should always be verified that the balloon is adequately inflated.

\subsubsection{Tube dislodgment}

\section{RECOMMENDATION}

ESGE recommends that in the case of early ( $<4$ weeks) tube dislodgment, "blind" tube reinsertion should be avoided. The patient should be monitored clinically and broad-spectrum antibiotics should be administered in symptomatic patients. A new PEG should be placed once the initial tract has healed.

Strong recommendation, low quality evidence.

\section{RECOMMENDATION}

ESGE recommends that in the case of late ( $>4$ weeks) tube dislodgment, a bedside balloon-type replacement tube, if available, can be immediately placed through the established tract. Otherwise, a Foley catheter can be used to maintain the tract as a temporary bridge to PEG tube replacement.

Strong recommendation, low quality evidence.

Tube dislodgment is considered to be a frequent PEG-associated AE. The incidence ranges from $13 \%$ to $29 \%[85,121$, 122]; apart from the association with major complications, tube dislodgment also results in significant healthcare costs [123].

In the vast majority of cases, tube dislodgment occurs towards the exterior of the abdominal wall, either by inappropriate manipulation of the tube or by accidental pulling, especially in patients with altered mental status or cognitive impairment.

Management of outer tube dislodgment depends on the time that it occurs, since the PEG tract is expected to mature within 4 weeks from placement [1]. Therefore, if dislodgment occurs after 4 weeks from initial placement, one can consider that the tract is mature and if a replacement balloon-type tube is available on site, this can be inserted through the pre-existing tract at the patient's bedside, without recourse to endoscopic visualization. If a replacement is not available and since the mature tract will start closing within the first 24 hours from tube dislodgment, the insertion of a temporary Foley catheter, in an attempt to keep the mature tract patent has been proposed $[124,125]$. However, the use of Foley catheters has been associated with high complication rates [125] and the evidence to recommend their use is considered to be of low quality [126]. In the case that replacement tube position is uncertain, direct endoscopic verification or use of a water-soluble contrast facilitated "tubogram" should be used to confirm the position.

In the case of tube dislodgment within the first 4 weeks of its insertion, there is a risk of gastric content leakage and consequent peritonitis, since the stomach may separate from the abdominal wall. In that case, "blind" tube replacement should be avoided, since it could lead to tube malposition in the perito- neal cavity. The patient should be kept nil-by-mouth, and broad-spectrum antibiotics should be administered. An attempt to place a new PEG tube at a different site of the abdominal wall may be performed, once the initial tract has healed [124].

Infrequently, a patient may present with abdominal pain and vomiting, as the result of gastric outflow obstruction from a distally dislodged PEG tube, causing post-pyloric blockage by the internal bumper or balloon. Clinical suspicion of internal migration, usually raised by the inappropriate position of the external bumper, can be confirmed endoscopically or radiologically. This event can easily be reversed by simply pulling the PEG tube back (after deflating the balloon in the case of a balloon-type tube) and fixing its external bumper in the correct position [127].

Various methods have been proposed to prevent tube dislodgment; these include sophisticated tube designs such as low profile "button-type" tubes $[128,129]$. In a recent RCT, balloon-tube dislodgment was significantly less frequent in a group of patients who underwent weekly measurement of the water volume within the balloon followed by tube replacement at 3-monthly intervals [130]. Cost concerns and tube-type selection would however hinder the general applicability of this strategy.

\subsubsection{Gastrocolocutaneous fistula}

This is a rare AE that occurs when the colon is accidentally punctured during PEG or D-PEJ placement. Its occurrence creates a fistulous tract through the gastric wall, colon, abdominal wall and finally the skin [131]. Its clinical appearance varies from asymptomatic to fecal leakage around the PEG site, frank perforation, or colonic obstruction. More often it usually becomes symptomatic once the initially placed tube is removed or replaced by another tube, the distal end of which is wrongly positioned within the transverse colon. In this case the patient presents with diarrhea once the enteral feeding is re-initiated [132]. Contrast-mediated radiographic imaging facilitates accurate diagnosis. The treatment of choice consists of PEG tube removal to allow the fistulous tract to heal. If this is unsuccessful, an endoscopic approach, using over-the-scope clips or full-thickness transmural sutures, or surgery (especially for persistent or complicated cases) have also been used [133-136].

\subsubsection{Gastrocutaneous fistula, after PEG removal}

\section{RECOMMENDATION}

ESGE recommends endoscopic modalities as the first-line management in the case of persisting gastrocutaneous fistula after PEG removal.

Strong recommendation, low quality evidence.

Healing of the gastrocutaneous tract usually starts within 24 hours of PEG removal and is often complete within a few days. In a limited number of cases it takes weeks for the tract to heal. However, in some cases the tract fails to heal and a gastrocutaneous fistula persists. Studies in children showed that a gastrocutaneous fistula developed in 1 out of 4 patients; longer PEG 
duration was associated with a higher likelihood of fistula formation $[137,138]$.

The presence of a fistulous tract is easily recognized by presence of persistent or periodic leakage of gastric fluid from the previous PEG site on the skin of the abdominal wall. Currently, different endoscopic modalities, mainly consisting of the use of through-the-scope or over-the-scope clips, as well as application of argon plasma coagulation and endoscopy-assisted suturing, offer promising results and have obviated the need for surgical intervention in most cases [133, 139-145].

\subsection{Post-placement instructions to carers for enteral tube maintenance}

\section{RECOMMENDATION}

ESGE suggests daily care of the PEG/PEG-J/D-PEJ site using a sterile saline solution and dressing application for the first week after placement. Loosening of the internal bumper after 3 to 5 days is suggested, and mobilization of the tube should begin from 7 to 10 days after placement.

Weak recommendation, low quality evidence.

After the percutaneous tube placement, the skin and the position of the tube should be checked every day. The external fixator should be placed tightly, $0.5 \mathrm{~cm}$ above the skin, to prevent leakage during the first 3 to 5 days [146]. During the first week, the peristomal skin must be kept clean with a sterile saline solution, which is then dried. Before handling, manual hygiene and the use of gloves is important to prevent infection. A dressing may be applied to absorb any potential exudate, but it is not considered mandatory [147]. In that regard, a sterile "Y"-shaped dressing should be placed under the external site and the disc plate to reduce the tension applied. Any dressings must be changed regularly. Occlusive dressing use is not recommended, because of an increased risk of skin maceration. Glycerin hydrogel wound dressing can be used as an alternative, since it has been associated with significantly reduced rate of peristomal infections during the first 2 weeks post-PEG placement [148]; if used, this should be changed once per week.

At 3 to 5 days after insertion, the external bumper can be loosened by up to $1 \mathrm{~cm}$. Only after 7 to 10 days should the tube be gently moved from 2 to $5 \mathrm{~cm}$ inward and outward in order to prevent future adhesion and BBS [146]. After this maneuver, the tube should be returned to and fixed in its initial position; the distance between the exit point of the tube and the abdominal wall should be marked with a permanent marker [146]. As already discussed in the cases of D-PE] and PEG-J, any rotation of such tubes should be avoided [149], since this could lead to jejunal volvulus (D-PEJ) or displacement of the jejunal extension (PEG-J) $[35,36]$. This is generalized to all percutaneous tubes in order to standardize the protocol of care independently of the type of enteral access used. After a gastropexy ("introducer" or "push" technique), the tube should be mobi- lized once the gastropexy tags have been removed (generally after 2 to 4 weeks).

After 7 to 10 days, the peristomal skin should be cleaned with soap and fresh tap water and then dried, twice a week. Patients are allowed to bathe, shower, and swim with a waterproof dressing thereafter [1].

\subsection{Administration of medications through an enteral tube}

\section{RECOMMENDATION}

ESGE suggests that the use of medication in liquid form is preferred; if crushed solid forms are administered through enteral tubes, these should be optimally flushed through, in order to avoid tube occlusion.

Weak recommendation, low quality evidence.

Medication administration through an enteral tube requires careful evaluation. Not all drugs are safe for enteral administration. Drug - nutrient or drug - drug interactions can impact efficacy and increase toxicity [75]. Tube size and placement site should be considered before the introduction of a medication. Narrow-bore tubes $(<12-\mathrm{Fr} ; 1 \mathrm{Fr}=0.33 \mathrm{~mm})$ ] are more comfortable but increase the risk of clogging [75]. An incorrect administration method could also lead to tube obstruction. The placement site of the tube may also affect drug absorption; the majority of drugs are absorbed within the small intestine but some are absorbed within the stomach. For medications with a high first-pass hepatic metabolism, jejunal access could increase their absorption and consequently, their systemic effects [150]. The administration process should also take into account the timing of drug delivery with respect to flushing protocols, administration of other medications, and the enteral nutrition regimen [75]. In this regard, an integrated training program for nurses delivered by a clinical pharmacist has been shown to significantly improve drug administration via enteral feeding tubes [151].

Drug dose adjustment may be required and liquid formulations are preferred, in order to prevent tube occlusion. Diluted liquid medication can help reduce osmolality shifts and enhance drug delivery rates. If specific liquid medication is unavailable or inappropriate, a solid formulation may have to be used. Tablets may be crushed to a powder for suspension and hard gelatin capsules may be opened and mixed with purified water. Distinct syringes (the recognized standard, ISO 80369-3 for enteral tubes ["ENFit"]) should be used when administering drugs through an enteral tube, in order to avoid accidental parenteral injection. Appropriate irrigation of the enteral tube is mandatory before any drug administration. The tube should be flushed with $30 \mathrm{~mL}$ of water [1]. The flush is repeated between medications and after the last administration. Enteral nutrition should be stopped 30 minutes before drug administration and may be restarted 30 to 60 minutes after [146]. In the case of a drug-nutrient interaction, enteral nutrition should be discontinued for 2 hours before drug administration. 


\subsection{Enteral tube replacement}

\section{RECOMMENDATION}

ESGE recommends PEG tube replacement in the case of tube fracture, dislodgment, degradation, persisting peristomal wound infection/leakage, or skin ulceration. Strong recommendation, low quality evidence.

\section{RECOMMENDATION}

ESGE recommends against routine replacement of PEG tubes with internal bumpers.

Strong recommendation, low quality evidence.

\section{RECOMMENDATION}

ESGE recommends replacement of balloon-type PEG tubes at 3- to 6-month intervals, or according to brand instructions, to prevent balloon failure.

Strong recommendation, low quality evidence.

There is no optimal evidence-based guideline regarding the replacement of non-balloon and balloon-type PEG tubes; however, there are several recommendations which can be divided into those concerning scheduled or unscheduled replacements. Indications for unscheduled replacement are catheter breakage, occlusions that cannot be resolved conservatively, dislodgment, or dysfunction. In addition, persisting peristomal infection/leakage after appropriate antibiotic treatment, fungal coIonization with material deterioration, and non-healing skin ulceration despite optimal wound care, may also be indications to remove and/or replace the tube $[1,75,152]$.

Scheduled replacements are dependent on the internal fixation type of the enteral tube. PEG tubes with internal bumpers are long-lasting; up to $70 \%$ can stay in place for more than 2 years $[20,153]$ and do not require scheduled replacement. Conversely, for balloon-type tubes, it is recommended to develop local protocols that reflect manufacturer guidelines, as balloon failure can occur and lead to tube dislodgment. Most balloon-type tubes have to be replaced regularly at 3- to 6month intervals $[20,130]$.

The balloon is deflated and retrieved, and a new balloontype tube is inserted and inflated with sterile water (not saline) according to specifications (usually 5 to $10 \mathrm{~mL}$ ) [62]. Water volume may be checked every week to prevent spontaneous balloon deflation because of water leakage [1].

Dislodged PEG tubes often demand emergency consultations in a frail patient population and should be managed appropriately as soon as possible [154].

\subsection{Definitive enteral tube removal}

\section{RECOMMENDATION}

ESGE recommends against removing a percutaneous enteral tube within 4 weeks of insertion.

Strong recommendation, low quality evidence.

\section{RECOMMENDATION}

ESGE suggests using the "cut and push" technique for removing enteral tubes with internal bumpers. However, in patients with previous bowel surgery, strictures, or ileus, endoscopic removal of the internal bumper is suggested. Weak recommendation, low quality evidence.

When a percutaneous enteral tube (PEG/PEG-J/D-PEJ) is no longer required, it should be removed. However, before removal, it is advisable to ensure that the patient is able to keep a stable weight for a couple of weeks, without EN support [1]. Furthermore, it usually takes up to 4 weeks after insertion for a percutaneous tract to mature, or even longer in frail patients with significant comorbidities [1]. Therefore, a percutaneous enteral tube should not be removed within 4 weeks of insertion, in order to avoid the risk of internal leakage and peritonitis.

For a bumper-type tube, removal is performed by cutting the tube at the abdominal skin level and pushing the internal bumper into the intestinal lumen with a blunt stylet ("cut and push" technique) $[155,156]$. This is particularly useful for patients with a D-PEJ, in whom endoscopic retrieval can be particularly challenging and invasive [36]. Endoscopic retrieval of the bumper is recommended in cases with previous bowel surgery and for patients at risk of strictures or ileus, which could hinder spontaneous migration and elimination of the tube remnant and bumper $[1,157,158]$.

\subsection{Optimal outpatient care for patients with enteral tubes}

\section{RECOMMENDATION}

ESGE recommends that patients with enteral tubes are regularly monitored by a dedicated multidisciplinary team (in collaboration with home caregivers, nurses, and general practitioners), for efficacy of EN support and for potential complications.

Strong recommendation, low quality evidence.

Despite the overall positive effect of home enteral nutrition, tube-related complications are frequent and can lead to a hospital readmission rate as high as $23 \%$ at 6 months [159]. A small prospective study of 8 patients with home enteral nutrition showed that, despite systematic monthly follow-up by a 
dedicated nurse, there was an average of 5.4 unscheduled healthcare contacts over 10.5 months, mostly for tube-related complications [160]. Therefore, monitoring after discharge should include not only surveillance of efficacy regarding enteral nutrition administration (weight, nutritional parameters, muscle strength, food intake), but also of tolerance (digestive tolerance, tube-related complications) [1]. The modalities of outpatient monitoring depend upon patient-related factors (underlying disease, nutritional status on discharge, active treatment or palliative care), and structure-related factors (home care or institution) [1]. In any case, communication between the in-hospital prescribing multidisciplinary nutrition team and the home or institution caregivers, as well as adequate training of the caregivers are crucial elements to assure optimal management.

In a prospective study involving 313 patients with PEG who were followed up by a dedicated team, 371 complications were encountered. Through this collaborative approach, most of these were resolved without recourse to hospitalization, resulting in a significant reduction of PEG-related hospital readmissions to $2 \%(P<0.0001)$ [159]. These encouraging results were echoed by the findings of an multicenter observational study from Poland, where collaborative care by a dedicated team was shown to reduce overall morbidity and costs relating to long-term home enteral nutrition [161].

\section{Disclaimer}

The legal disclaimer for ESGE guidelines [5] applies to this Guideline.

\section{Acknowledgment}

The authors are grateful to Dr. Robert Verdonk of the Department of Gastroenterology and Hepatology, St Antonius Hospital, Nieuwegein, The Netherlands, and Dr. Cesare Hassan of the Gastroenterology Unit, Nuovo Regina Margherita Hospital, Rome, Italy, for their review of the manuscript.

\section{Competing interests}

\footnotetext{
T. Beyna receives consultancy honoraria and lecture fees from Olympus and Boston Scientific (ongoing), and lecture fees from Medtronic, the Falk Foundation, and Erbe. E.J. Despott has received consultancy fees and speaker's honoraria from Boston Scientific, Ambu, and Fujifilm (2007 to 2019); his department has received educational grants from Fujifilm, Pentax, Olympus, Boston Scientific, Norgine, Cook, Erbe, Medtronic, Ankon, Diagmed, and US Endoscopy (2017 to 2019). S.M. Schneider has been a board member for Nutricia France (2016 to 2018); he has been or is a consultant for Laboratoires Grand Fontaine (2013), Nestlé Health Sciences (2020), and Baxter (2019). J. E. van Hooft has received lecture fees from Medtronic (2014 to 2015, 2019) and Cook Medical (2019), and consultancy fees from Boston Scientific (2014 to 2017); her department has received research grants from Cook Medical (2014 to 2019), and Abbott (2014 to 2017). M. Arvanitakis, A. Ballarin, K. Boeykens, P. Elbe, I. Gisbertz, P. Gkolfakis, A. Hoyois, O. Mosteanu, D. Sanders, and P. ThelinSchmidt declare that they have no conflicts of interest.
}

\section{References}

[1] Bischoff SC, Austin P, Boeykens K et al. ESPEN guideline on home enteral nutrition. Clin Nutr 2020; 39: 5-22

[2] Kurien M, Westaby D, Romaya C et al. National survey evaluating service provision for percutaneous endoscopic gastrostomy within the UK. Scand J Gastroenterol 2011; 46: 1519-1524

[3] Hucl T, Spicak J. Complications of percutaneous endoscopic gastrostomy. Best Pract Res Clin Gastroenterol 2016; 30: 769-781

[4] Arvanitakis M, Gkolfakis P, Despott EJ et al. Endoscopic management of enteral tubes in adult patients - Part 1: Definitions and indications. European Society of Gastrointestinal Endoscopy (ESGE) Guideline. Endoscopy 2020; 52: 81-92

[5] Dumonceau JM, Hassan C, Riphaus A et al. European Society of Gastrointestinal Endoscopy (ESGE) Guideline Development Policy. Endoscopy 2012; 44: 626-629

[6] Palmer LB, McClave SA, Bechtold ML et al. Tips and tricks for deep jejunal enteral access: modifying techniques to maximize success. Curr Gastroenterol Rep 2014; 16: 409

[7] Hirdes MM, Monkelbaan JF, Haringman J] et al. Endoscopic clipassisted feeding tube placement reduces repeat endoscopy rate: results from a randomized controlled trial. Am J Gastroenterol 2012; 107: $1220-1227$

[8] ASGE Technology Committee; Kwon RS, Banerjee S, Desilets D et al. Enteral nutrition access devices. Gastrointest Endosc 2010; 72: 236 248

[9] Gauderer MW, Ponsky JL, Izant RJ et al. Gastrostomy without laparotomy: a percutaneous endoscopic technique. J Pediatr Surg 1980; 15: 872-875

[10] Loser C, Aschl G, Hebuterne X et al. ESPEN guidelines on artificial enteral nutrition - percutaneous endoscopic gastrostomy (PEG). Clin Nutr 2005; 24: 848-861

[11] Stiegmann GV, Goff JS, Silas D et al. Endoscopic versus operative gastrostomy: final results of a prospective randomized trial. Gastrointest Endosc 1990; 36: 1-5

[12] Larson DE, Burton DD, Schroeder KW et al. Percutaneous endoscopic gastrostomy. Indications, success, complications, and mortality in 314 consecutive patients. Gastroenterology 1987; 93: 4852

[13] Hull MA, Rawlings ], Murray FE et al. Audit of outcome of long-term enteral nutrition by percutaneous endoscopic gastrostomy. Lancet 1993; 341: 869-872

[14] Russell TR, Brotman M, Norris F. Percutaneous gastrostomy. A new simplified and cost-effective technique. Am J Surg 1984; 148: 132137

[15] Siu J, Fuller K, Nadler A et al. Metastasis to gastrostomy sites from upper aerodigestive tract malignancies: a systematic review and meta-analysis. Gastrointest Endosc 2020; 91: 1005-1014 e1017

[16] Dewald CL, Hiette PO, Sewall LE et al. Percutaneous gastrostomy and gastrojejunostomy with gastropexy: experience in 701 procedures. Radiology 1999; 211: 651-656

[17] Chadha KS, Thatikonda C, Schiff M et al. Outcomes of percutaneous endoscopic gastrostomy tube placement using a T-fastener gastropexy device in head and neck and esophageal cancer patients. Nutr Clin Pract 2010; 25: 658-662

[18] Dormann AJ, Glosemeyer R, Leistner U et al. Modified percutaneous endoscopic gastrostomy (PEG) with gastropexy - early experience with a new introducer technique. Z Gastroenterol 2000; 38: 933938 
[19] Shastri YM, Hoepffner N, Tessmer A et al. New introducer PEG gastropexy does not require prophylactic antibiotics: multicenter prospective randomized double-blind placebo-controlled study. Gastrointest Endosc 2008; 67: 620-628

[20] Itkin M, DeLegge MH, Fang JC et al. Multidisciplinary practical guidelines for gastrointestinal access for enteral nutrition and decompression from the Society of Interventional Radiology and American Gastroenterological Association (AGA) Institute, with endorsement by Canadian Interventional Radiological Association (CIRA) and Cardiovascular and Interventional Radiological Society of Europe (CIRSE). Gastroenterology 2011; 141: 742-765

[21] Hogan RB, DeMarco DC, Hamilton JK et al. Percutaneous endoscopic gastrostomy - to push or pull. A prospective randomized trial. Gastrointest Endosc 1986; 32: 253-258

[22] Sartori S, Trevisani L, Nielsen I et al. Percutaneous endoscopic gastrostomy placement using the pull-through or push-through techniques: is the second pass of the gastroscope necessary? Endoscopy 1996; 28: 686-688

[23] Dormann A], Huchzermeyer H. Endoscopic techniques for enteral nutrition: standards and innovations. Dig Dis 2002; 20: 145-153

[24] Blumenstein I, Shastri YM, Stein J. Gastroenteric tube feeding: techniques, problems and solutions. World J Gastroenterol 2014; 20: 8505-8524

[25] DeLegge MH, Patrick P, Gibbs R. Percutaneous endoscopic gastrojejunostomy with a tapered tip, nonweighted jejunal feeding tube: improved placement success. Am J Gastroenterol 1996; 91: 11301134

[26] Adler DG, Gostout C], Baron TH. Percutaneous transgastric placement of jejunal feeding tubes with an ultrathin endoscope. Gastrointest Endosc 2002; 55: 106-110

[27] Baskin W, Johanson JF. Trans-PEG ultra thin endoscopy for PEG/J placement. Gastrointest Endosc 2003; 57: 146 ; author reply 146147

[28] Leichus L, Patel R, Johlin F. Percutaneous endoscopic gastrostomy/ jejunostomy (PEG/PEJ) tube placement: a novel approach. Gastrointest Endosc 1997; 45: 79-81

[29] MacFadyen BV Jr, Catalano MF, Raijman I et al. Percutaneous endoscopic gastrostomy with jejunal extension: a new technique. Am J Gastroenterol 1992; 87: 725-728

[30] Bumpers HL, Luchette FA, Doerr R] et al. A simple technique for insertion of PEJ via PEG. Surg Endosc 1994; 8: 121-123

[31] Parasher VK, Abramowicz C], Bell C et al. Successful placement of percutaneous gastrojejunostomy using steerable glidewire - a modified controlled push technique. Gastrointest Endosc 1995; 41: 52-55

[32] DeLegge MH, Duckworth PFJr, McHenry LJr et al. Percutaneous endoscopic gastrojejunostomy: a dual center safety and efficacy trial. JPEN J Parenter Enteral Nutr 1995; 19: 239-243

[33] Udorah MO, Fleischman MW, Bala V et al. Endoscopic clips prevent displacement of intestinal feeding tubes: a long-term follow-up study. Dig Dis Sci 2010; 55: 371-374

[34] Fan AC, Baron TH, Rumalla A et al. Comparison of direct percutaneous endoscopic jejunostomy and PEG with jejunal extension. Gastrointest Endosc 2002; 56: 890-894

[35] Maple JT, Petersen BT, Baron TH et al. Direct percutaneous endoscopic jejunostomy: outcomes in 307 consecutive attempts. Am J Gastroenterol 2005; 100: 2681-2688

[36] Toussaint E, Van Gossum A, Ballarin A et al. Percutaneous endoscopic jejunostomy in patients with gastroparesis following lung transplantation: feasibility and clinical outcome. Endoscopy 2012; 44: 772-775
[37] Mellert J, Naruhn MB, Grund KE et al. Direct endoscopic percutaneous jejunostomy (EPJ). Clinical results. Surg Endosc 1994; 8: 867869 ; discussion 869-870

[38] Simoes PK, Woo KM, Shike M et al. Direct percutaneous endoscopic jejunostomy: procedural and nutrition outcomes in a large patient cohort. JPEN J Parenter Enteral Nutr 2018; 42: 898-906

[39] Aktas H, Mensink PB, Kuipers E] et al. Single-balloon enteroscopyassisted direct percutaneous endoscopic jejunostomy. Endoscopy 2012; 44: 210-212

[40] Despott E], Gabe S, Tripoli E et al. Enteral access by double-balloon enteroscopy: an alternative method of direct percutaneous endoscopic jejunostomy placement. Dig Dis Sci 2011; 56: 494-498

[41] Karhadkar AS, Rengen MR, Dubin EH et al. Direct percutaneous endoscopic jejunostomy tube placement using a fine needle for jejunal anchoring. Endoscopy 2006; 38: 952

[42] Adachi Y, Akino K, Mita $\mathrm{H}$ et al. Systemic prophylactic antibiotics for the modified introducer method for percutaneous endoscopic gastrostomy: a prospective, randomized, double-blind study. J Clin Gastroenterol 2016; 50: 727-732

[43] Blomberg J, Lagergren P, Martin L et al. Novel approach to antibiotic prophylaxis in percutaneous endoscopic gastrostomy (PEG): randomised controlled trial. BMJ 2010; 341: c3115

[44] Radhakrishnan NV, Shenoy AH, Cartmill I et al. Addition of local antiseptic spray to parenteral antibiotic regimen reduces the incidence of stomal infection following percutaneous endoscopic gastrostomy: A randomized controlled trial. Eur J Gastroenterol Hepatol 2006; 18: $1279-1284$

[45] Saadeddin A, Freshwater DA, Fisher NC et al. Antibiotic prophylaxis for percutaneous endoscopic gastrostomy for non-malignant conditions: a double-blind prospective randomized controlled trial. Aliment Pharmacol Ther 2005; 22: 565-570

[46] Panigrahi H, Shreeve DR, Tan WC et al. Role of antibiotic prophylaxis for wound infection in percutaneous endoscopic gastrostomy (PEG): result of a prospective double-blind randomized trial. J Hosp Infect 2002; 50: 312-315

[47] Dormann AJ, Wigginghaus B, Risius $\mathrm{H}$ et al. Antibiotic prophylaxis in percutaneous endoscopic gastrostomy (PEG) - results from a prospective randomized multicenter trial. Z Gastroenterol 2000; 38: 229-234

[48] Ahmad I, Mouncher A, Abdoolah A et al. Antibiotic prophylaxis for percutaneous endoscopic gastrostomy - a prospective, randomised, double-blind trial. Aliment Pharmacol Ther 2003; 18: 209-215

[49] Preclik G, Grune S, Leser HG et al. Prospective, randomised, double blind trial of prophylaxis with single dose of co-amoxiclav before percutaneous endoscopic gastrostomy. BMJ 1999; 319: 881-884

[50] Gossner L, Keymling J, Hahn EG et al. Antibiotic prophylaxis in percutaneous endoscopic gastrostomy (PEG): a prospective randomized clinical trial. Endoscopy 1999; 31: 119-124

[51] Akkersdijk WL, van Bergeijk JD, van Egmond T et al. Percutaneous endoscopic gastrostomy (PEG): comparison of push and pull methods and evaluation of antibiotic prophylaxis. Endoscopy 1995; 27: 313-316

[52] Sturgis TM, Yancy W, Cole JC et al. Antibiotic prophylaxis in percutaneous endoscopic gastrostomy. Am J Gastroenterol 1996; 91: 2301-2304

[53] Jain NK, Larson DE, Schroeder KW et al. Antibiotic prophylaxis for percutaneous endoscopic gastrostomy. A prospective, randomized, double-blind clinical trial. Ann Intern Med 1987; 107: 824-828

[54] Jonas SK, Neimark S, Panwalker AP. Effect of antibiotic prophylaxis in percutaneous endoscopic gastrostomy. Am J Gastroenterol 1985; 80: $438-441$ 
[55] Jafri NS, Mahid SS, Minor KS et al. Meta-analysis: antibiotic prophylaxis to prevent peristomal infection following percutaneous endoscopic gastrostomy. Aliment Pharmacol Ther 2007; 25: 647-656

[56] Lipp A, Lusardi G. Systemic antimicrobial prophylaxis for percutaneous endoscopic gastrostomy. Cochrane Database Syst Rev 2013: doi:10.1002/14651858.CD005571.pub3

[57] ASGE Standards of Practice Committee; Khashab MA, Chithadi KV, Acosta RD et al. Antibiotic prophylaxis for $\mathrm{Gl}$ endoscopy. Gastrointest Endosc 2015; 81: 81-89

[58] Vujasinovic M, Ingre C, Baldaque Silva F et al. Complications and outcome of percutaneous endoscopic gastrostomy in a high-volume centre. Scand J Gastroenterol 2019; 54: 513-518

[59] DeLegge M. Gastrostomy tubes: Complications and their management. UpToDate. https://www.uptodate.com/contents/gastrostomy-tubes-complications-and-their-management/print\#!

[60] Singh A, Gelrud A. Adverse events associated with percutaneous enteral access. Gastrointest Endosc Clin N Am 2015; 25: 71-82

[61] Sutcliffe J, Wigham A, McEniff $N$ et al. CIRSE standards of practice guidelines on gastrostomy. Cardiovasc Intervent Radiol 2016; 39 : 973-987

[62] Toussaint E, Van Gossum A, Ballarin A et al. Enteral access in adults. Clin Nutr 2015; 34: 350-358

[63] Delgado AAA, de Moura DTH, Ribeiro IB et al. Propofol vs traditional sedatives for sedation in endoscopy: A systematic review and metaanalysis. World J Gastrointest Endosc 2019; 11: 573-588

[64] Metheny NA, Krieger MM, Healey F et al. A review of guidelines to distinguish between gastric and pulmonary placement of nasogastric tubes. Heart Lung 2019; 48: 226-235

[65] Rassias AJ, Ball PA, Corwin HL. A prospective study of tracheopulmonary complications associated with the placement of narrowbore enteral feeding tubes. Crit Care 1998; 2: 25-28

[66] Sorokin R, Gottlieb JE. Enhancing patient safety during feeding-tube insertion: a review of more than 2,000 insertions. JPEN J Parenter Enteral Nutr 2006; 30: 440-445

[67] Lai CW, Barlow R, Barnes M et al. Bedside placement of nasojejunal tubes: a randomised-controlled trial of spiral- vs straight-ended tubes. Clin Nutr 2003; 22: 267-270

[68] Wojtowycz MM, Arata JA Jr, Micklos T] et al. CT findings after uncomplicated percutaneous gastrostomy. AJR Am J Roentgenol 1988; 151: 307-309

[69] Singh D, Laya AS, Vaidya OU et al. Risk of bleeding after percutaneous endoscopic gastrostomy (PEG). Dig Dis Sci 2012; 57: 973-980

[70] Wiggins TF, Kaplan R, DeLegge MH. Acute hemorrhage following transhepatic PEG tube placement. Dig Dis Sci 2007; 52: 167-169

[71] Paski SC, Dominitz JA. Endoscopic solutions to challenging enteral feeding problems. Curr Opin Gastroenterol 2012; 28: 427-431

[72] Westaby D, Young A, O'Toole P et al. The provision of a percutaneously placed enteral tube feeding service. Gut 2010; 59: 15921605

[73] Turgay AS, Khorshid L. Effectiveness of the auscultatory and $\mathrm{pH}$ methods in predicting feeding tube placement. J Clin Nurs 2010; 19 : 1553-1559

[74] Metheny NA, Meert KL. Monitoring feeding tube placement. Nutr Clin Pract 2004; 19: 487-495

[75] Boullata JI, Carrera AL, Harvey L et al. ASPEN safe practices for enteral nutrition therapy [Formula: see text]. JPEN J Parenter Enteral Nutr 2017; 41: 15-103

[76] Burgos R, Breton I, Cereda E et al. ESPEN guideline clinical nutrition in neurology. Clin Nutr 2018; 37: 354-396

[77] Rowat AM, Graham C, Dennis M. Diagnostic accuracy of a pH stick, modified to detect gastric lipase, to confirm the correct placement of nasogastric tubes. BMJ Open Gastroenterol 2018; 5: e000218
[78] Rowat AM, Graham C, Dennis M. Study to determine the likely accuracy of $\mathrm{pH}$ testing to confirm nasogastric tube placement. BMJ Open Gastroenterol 2018; 5: e000211

[79] Chau JP, Lo SH, Thompson DR et al. Use of end-tidal carbon dioxide detection to determine correct placement of nasogastric tube: a meta-analysis. Int J Nurs Stud 2011; 48: 513-521

[80] Torsy T, Saman R, Boeykens K et al. Comparison of two methods for estimating the tip position of a nasogastric feeding tube: a randomized controlled trial. Nutr Clin Pract 2018; 33: 843-850

[81] Maple JT, Petersen BT, Baron TH et al. Abdominal CT as a predictor of outcome before attempted direct percutaneous endoscopic jejunostomy. Gastrointest Endosc 2006; 63: 424-430

[82] Bechtold ML, Matteson ML, Choudhary A et al. Early versus delayed feeding after placement of a percutaneous endoscopic gastrostomy: a meta-analysis. Am J Gastroenterol 2008; 103: 2919-2924

[83] Szary NM, Arif M, Matteson ML et al. Enteral feeding within three hours after percutaneous endoscopic gastrostomy placement: a meta-analysis. J Clin Gastroenterol 2011; 45: e34-38

[84] Vyawahare MA, Shirodkar M, Gharat A et al. A comparative observational study of early versus delayed feeding after percutaneous endoscopic gastrostomy. Indian J Gastroenterol 2013; 32: 366-368

[85] Anderloni A, Di Leo M, Barzaghi F et al. Complications and early mortality in percutaneous endoscopic gastrostomy placement in lombardy: A multicenter prospective cohort study. Dig Liver Dis 2019; 51: 1380-1387

[86] Schneider AS, Schettler A, Markowski A et al. Complication and mortality rate after percutaneous endoscopic gastrostomy are low and indication-dependent. Scand J Gastroenterol 2014; 49: 891898

[87] Pih GY, Na HK, Ahn JY et al. Risk factors for complications and mortality of percutaneous endoscopic gastrostomy insertion. BMC Gastroenterol 2018; 18: 101

[88] Blomberg J, Lagergren P, Martin L et al. Albumin and C-reactive protein levels predict short-term mortality after percutaneous endoscopic gastrostomy in a prospective cohort study. Gastrointest Endosc 2011; 73: 29-36

[89] Sbeit W, Kadah A, Mari A et al. Simple bedside predictors of survival after percutaneous gastrostomy tube insertion. Can J Gastroenterol Hepatol 2019; 2019: 1532918

[90] Kara O, Kizilarslanoglu MC, Canbaz B et al. Survival after percutaneous endoscopic gastrostomy in older adults with neurologic disorders. Nutr Clin Pract 2016; 31: 799-804

[91] Clarke E, Pitts N, Latchford A et al. A large prospective audit of morbidity and mortality associated with feeding gastrostomies in the community. Clin Nutr 2017; 36: 485-490

[92] Lee C, Im JP, Kim JW et al. Risk factors for complications and mortality of percutaneous endoscopic gastrostomy: a multicenter, retrospective study. Surg Endosc 2013; 27: 3806-3815

[93] Barbosa M, Magalhaes ], Marinho C et al. Predictive factors of early mortality after percutaneous endoscopic gastrostomy placement: The importance of C-reactive protein. Clin Nutr ESPEN 2016; 14: 1923

[94] Rahnemai-Azar AA, Rahnemaiazar AA, Naghshizadian R et al. Percutaneous endoscopic gastrostomy: indications, technique, complications and management. World J Gastroenterol 2014; 20: 7739-7751

[95] Zopf Y, Konturek P, Nuernberger A et al. Local infection after placement of percutaneous endoscopic gastrostomy tubes: a prospective study evaluating risk factors. Can J Gastroenterol 2008; 22: 987-991

[96] Krishna S, Singh S, Dinesh KR et al. Percutaneous endoscopic gastrostomy (PEG) site infections: a clinical and microbiological study from university teaching hospital, India. J Infect Prev 2015; 16: 113 116 
[97] Artul S, Nseir W, Assaf $\mathrm{V}$ et al. Abdominal wall necrotising fasciitis due to dislodged percutaneous endoscopic gastrostomy tube. BM] Case Rep 2014: doi:10.1136/bcr-2013-201346

[98] MacLean AA, Miller G, Bamboat ZM et al. Abdominal wall necrotizing fasciitis from dislodged percutaneous endoscopic gastrostomy tubes: a case series. Am Surg 2004; 70: 827-831

[99] Klein S, Heare BR, Soloway RD. The "buried bumper syndrome": a complication of percutaneous endoscopic gastrostomy. Am J Gastroenterol 1990; 85: 448-451

[100] El AZ, Arvanitakis M, Ballarin A et al. Buried bumper syndrome: low incidence and safe endoscopic management. Acta Gastroenterol Belg 2011; 74: 312-316

[101] Chung RS, Schertzer M. Pathogenesis of complications of percutaneous endoscopic gastrostomy. A lesson in surgical principles. Am Surg 1990; 56: 134-137

[102] McClave SA, Chang WK. Complications of enteral access. Gastrointest Endosc 2003; 58: 739-751

[103] Cyrany J, Rejchrt S, Kopacova M, Bures J. Buried bumper syndrome: A complication of percutaneous endoscopic gastrostomy. World J Gastroenterol 2016; 22: 618-627

[104] Mueller-Gerbes D, Hartmann B, Lima JP et al. Comparison of removal techniques in the management of buried bumper syndrome: a retrospective cohort study of 82 patients. Endosc Int Open 2017; 5: E603-E607

[105] Boyd JW, DeLegge MH, Shamburek RD et al. The buried bumper syndrome: a new technique for safe, endoscopic PEG removal. Gastrointest Endosc 1995; 41: 508-511

[106] Gencosmanoglu R, Koc D, Tozun N. The buried bumper syndrome: migration of internal bumper of percutaneous endoscopic gastrostomy tube into the abdominal wall. J Gastroenterol 2003; 38: 10771080

[107] Costa D, Despott EJ, Lazaridis $\mathrm{N}$ et al. Minimally invasive endoscopic management of buried bumper syndrome by use of a novel dedicated resection device. VideoGIE 2019; 4: 366-368

[108] Hindryckx P, Dhooghe B, Wannhoff A. A novel device for the endoscopic management of buried bumper syndrome. Endoscopy 2019; 51: 689-693

[109] Wolpert LE, Summers DM, Tsang A. Novel endoscopic management of buried bumper syndrome in percutaneous endoscopic gastrostomy: The Olympus HookKnife. World J Gastroenterol 2017; 23: 65466548

[110] Casper M, Lammert F. How to improve success rates of endoscopic management for buried bumper syndrome. QJM 2018; 111: 467472

[111] Venu RP, Brown RD, Pastika BJ et al. The buried bumper syndrome: a simple management approach in two patients. Gastrointest Endosc 2002; 56: 582-584

[112] Peck J, Sapp K, Wilsey A et al. Wire guided cannulation facilitates endoscopic management of buried bumper syndrome: a novel technique. Pediatr Gastroenterol Hepatol Nutr 2019; 22: 86-89

[113] Navarro F, Loflin C, Diegidio P et al. Herniation through gastrostomy site: Case report. Int J Surg Case Rep 2016; 25: 165-166

[114] Ozutemiz O, Oruc N, Tekin F et al. Ventral abdominal herniation through PEG site in a child with cystic fibrosis. Endoscopy 2007; 39: (Suppl. 01): E281

[115] Kaplan R, Delegge M. An unusual case of a ventral Richter's hernia at the site of a previous PEG tube. Dig Dis Sci 2006; 51: 2389-2392

[116] Boldo-Roda E, Peris-Trias A, de Lucia-Penalver GP et al. Reflections in front of a case of ventral hernia after PEG tube removal. Gastrointest Endosc 2005; 62: 323-324

[117] Chuang CH, Chen CY. Gastric herniation through PEG site. Gastrointest Endosc 2003; 58: 416
[118] Kachare MD, Rossi A], Mahpour NY et al. Incisional hernia after percutaneous endoscopic gastrostomy tube placement: importance of avoiding the linea alba. ACG Case Rep J 2019; 6: e00120

[119] Burney RE, Bryner BS. Safety and long-term outcomes of percutaneous endoscopic gastrostomy in patients with head and neck cancer. Surg Endosc 2015; 29: 3685-3689

[120] Conroy T. The prevention and management of complications associated with established percutaneous gastrostomy tubes in adults: a systematic review. JBI Libr Syst Rev 2009; 7: 1-37

[121] Rosenberger LH, Newhook T, Schirmer B et al. Late accidental dislodgement of a percutaneous endoscopic gastrostomy tube: an underestimated burden on patients and the health care system. Surg Endosc 2011; 25: 3307-3311

[122] Ridtitid W, Lehman GA, Watkins JL et al. Short and long-term outcomes from percutaneous endoscopic gastrostomy with jejunal extension. Surg Endosc 2017; 31: 2901-2909

[123] Kulvatunyou N, Zimmerman SA, Sadoun M et al. Comparing outcomes between "pull" versus "push" percutaneous endoscopic gastrostomy in acute care surgery: under-reported pull percutaneous endoscopic gastrostomy incidence of tube dislodgement. J Surg Res 2018; 232: 56-62

[124] Schrag SP, Sharma R, Jaik NP et al. Complications related to percutaneous endoscopic gastrostomy (PEG) tubes. A comprehensive clinical review. J Gastrointestin Liver Dis 2007; 16: 407-418

[125] Metussin A, Sia R, Bakar S et al. Foley catheters as temporary gastrostomy tubes: experience of a nurse-led service. Gastroenterol Nurs 2016; 39: 273-277

[126] Gray C, Grobelna A. Urinary catheters as replacement feeding tubes: a review of clinical effectiveness, cost-effectiveness, and guidelines. May 14, 2019. Ottawa, Ontario: Canadian Agency for Drugs and Technologies in Health;https://www.ncbi.nlm.nih.gov/books/ NBK545814/

[127] Shah J, Sunkara T, Yarlagadda KS et al. Gastric outlet and duodenal obstruction as a complication of migrated gastrostomy tube: report of two cases and literature review. Gastroenterology Res 2018; 11: $71-74$

[128] Rosenberger LH, Guidry CA, Davis JP et al. Reducing accidental dislodgement of the percutaneous endoscopic gastrostomy: a prospective trial of the "safetybreak" device. Surg Innov 2016; 23: 6269

[129] Kvello M, Knatten CK, Perminow G et al. Initial experience with percutaneous endoscopic gastrostomy with T-fastener fixation in pediatric patients. Endosc Int Open 2018; 6: E179-E185

[130] Shah J, Shahidullah A, Richards S. Reducing the unintended dislodgement of gastrostomy tubes in a long-term acute care hospital: A QA/QI pilot study. Gastroenterology Res 2018; 11: 369-373

[131] Okutani D, Kotani K, Makihara S. A case of gastrocolocutaneous fistula as a complication of percutaneous endoscopic gastrostomy. Acta Med Okayama 2008; 62: 135-138

[132] Lee J, Kim J, Kim HI et al. Gastrocolocutaneous fistula: an unusua case of gastrostomy tube malfunction with diarrhea. Clin Endosc 2018; 51: 196-200

[133] Ligresti D, Barbuscio I, Granata A et al. Endoscopic closure of gastrocolocutaneous fistula following percutaneous endoscopic gastrostomy, by OverStitch Endoscopic Suturing System. Endoscopy 2019; 51: E384-E385

[134] Rodrigues-Pinto E, Santos AL, Macedo G. Endoscopic closure of a colocutaneous fistula after placement of percutaneous endoscopic gastrostomy. Endoscopy 2019: doi:10.1055/a-1063-6276

[135] Nunes G, Paiva de Oliveira G, Cruz ] et al. Long-term gastrocolocutaneous fistula after endoscopic gastrostomy: how concerned should we be? GE Port J Gastroenterol 2019; 26: 441-447 
[136] Murino A, Despott EJ, Vaizey C et al. First report of endoscopic closure of a gastrocolic fistula using an over-the-scope clip system (with video). Gastrointest Endosc 2012; 75: 893; discussion 894

[137] Janik TA, Hendrickson RJ, Janik JS et al. Analysis of factors affecting the spontaneous closure of a gastrocutaneous fistula. J Pediatr Surg 2004; 39: 1197-1199

[138] El-Rifai N, Michaud L, Mention K et al. Persistence of gastrocutaneous fistula after removal of gastrostomy tubes in children: prevalence and associated factors. Endoscopy 2004; 36: 700-704

[139] Hameed H, Kalim S, Khan YI. Closure of a nonhealing gastrocutanous fistula using argon plasma coagulation and endoscopic hemoclips. Can J Gastroenterol 2009; 23: 217-219

[140] Martinez-Alcala Garcia A, Augustus ], Thakar K et al. Dual endoscopic technique using through- and over-the-scope clips to close a cologastrocutaneous fistula due to a percutaneous gastrostomy tube. Endoscopy 2017; 49: E64-E65

[141] Heinrich H, Gubler C, Valli PV. Over-the-scope-clip closure of long lasting gastrocutaneous fistula after percutaneous endoscopic gastrostomy tube removal in immunocompromised patients: A single center case series. World J Gastrointest Endosc 2017; 9: 85-90

[142] Gay-Chevallier S, Lupu A, Rivory ] et al. Closure of non-healing gastrocutaneous fistula after percutaneous endoscopic gastrostomy by endoscopic submucosal dissection and over-the-scope clip. Endoscopy 2019; 51: E125-E126

[143] Silva HM, Lima R, Pereira F et al. Endoscopy-assisted suture of gastrocutaneous fistula: a promising approach in pediatric patients. Am J Gastroenterol 2018; 113: 1562-1564

[144] Singhal S, Changela K, Culliford A et al. Endoscopic closure of persistent gastrocutaneous fistulae, after percutaneous endoscopic gastrostomy (PEG) tube placement, using the over-the-scope-clip system. Therap Adv Gastroenterol 2015; 8: 182-188

[145] Brindley JH, Yip B, Vlachou E et al. Successful endoscopic closure of a gastrocutaneous fistula using a 'Padlock Clip'. Endoscopy 2016; 48: (Suppl. 01): E115-116

[146] Roveron G, Antonini M, Barbierato M et al. Clinical practice guidelines for the nursing management of percutaneous endoscopic gastrostomy and jejunostomy (PEG/PEJ) in adult patients: an executive summary. J Wound Ostomy Continence Nurs 2018; 45: 326-334

[147] Clinical Resource Efficiency Support Team (CREST); Guidelines for the management of enteral tube feeding in adults. 2004: https:// www.irspen.ie/wp-content/uploads/2014/10/CREST_Guidelines_for_the_management_of_enteral_tube_feeding_in_adults.pdf

[148] Blumenstein I, Borger D, Loitsch S et al. A glycerin hydrogel-based wound dressing prevents peristomal infections after percutaneous endoscopic gastrostomy (PEG): a prospective, randomized study. Nutr Clin Pract 2012; 27: 422-425
[149] McClave SA, Jafri NS. Spectrum of morbidity related to bolster placement at time of percutaneous endoscopic gastrostomy: buried bumper syndrome to leakage and peritonitis. Gastrointest Endosc Clin N Am 2007; 17: 731-746

[150] Williams NT. Medication administration through enteral feeding tubes. Am J Health Syst Pharm 2008; 65: 2347-2357

[151] Hossaini Alhashemi S, Ghorbani R, Vazin A. Improving knowledge, attitudes, and practice of nurses in medication administration through enteral feeding tubes by clinical pharmacists: a case-control study. Adv Med Educ Pract 2019; 10: 493-500

[152] McClave SA, DiBaise JK, Mullin GE et al. ACG clinical guideline: nutrition therapy in the adult hospitalized patient. Am J Gastroenterol 2016; 111: 315-334; quiz 335

[153] Siau K, Troth T, Gibson E et al. How long do percutaneous endoscopic gastrostomy feeding tubes last? A retrospective analysis Postgrad Med J 2018; 94: 469-474

[154] Villela EL, Sakai P, Almeida MR et al. Endoscopic gastrostomy replacement tubes: long-term randomized trial with five silicone commercial models. Clin Nutr 2014; 33: 221-225

[155] Pearce CB, Goggin PM, Collett J et al. The "cut and push" method of percutaneous endoscopic gastrostomy tube removal. Clin Nutr 2000; 19: 133-135

[156] Agha A, AlSaudi D, Furnari M et al. Feasibility of the cut-and-push method for removing large-caliber soft percutaneous endoscopic gastrostomy devices. Nutr Clin Pract 2013; 28: 490-492

[157] Peacock O, Singh R, Cole A, Speake W. The "cut and push" technique: is it really safe? BMJ Case Rep 2012: doi:10.1136/bcr-2012006607

[158] Pratt J, Green S. Removal of percutaneous endoscopic gastrostomy tubes in adults using the "cut and push" method: A systematic review. Clin Nutr ESPEN 2017; 21: 59-65

[159] Kurien M, White S, Simpson G et al. Managing patients with gastrostomy tubes in the community: can a dedicated enteral feed dietetic service reduce hospital readmissions? Eur J Clin Nutr 2012; 66: 757-760

[160] Crosby J, Duerksen DR. A prospective study of tube- and feedingrelated complications in patients receiving long-term home enteral nutrition. JPEN J Parenter Enteral Nutr 2007; 31: 274-277

[161] Klek S, Hermanowicz A, Dziwiszek G et al. Home enteral nutrition reduces complications, length of stay, and health care costs: results from a multicenter study. Am J Clin Nutr 2014; 100: 609-615 